\title{
Effect of exogenous hormones on leaf yellowing in cut flowering branches of Alstroemeria pelegrina L.*
}

\author{
Wouter G. van Doorn' ${ }^{\text {, Jitske Hibma }}{ }^{2}$ \& Janny de Wit ${ }^{1}$ \\ 'Agrotechnological Research Institute, P.O. Box 17,6700 AA Wageningen, The Netherlands \\ ${ }^{2}$ Centre for Agrobiological Research, P.O. Box 14, 6700 AA Wageningen, The Netherlands
}

Key words: Alstroemeria pelegrina L. cut flowers, leaf yellowing, hormones, GA, IAA, kinetin

\begin{abstract}
Inclusion of IAA in the vase water had little effect on leaf yellowing in cut flowering branches of Alstroemeria pelegrina $\mathrm{L}$. while kinetin delayed leaf yellowing at $10^{-4} \mathrm{M}$ (continuous treatment). Chlorophyll was effectively retained by $10^{-7} \mathrm{M}$ gibberellic acid (GA) in the vase water or by a $20 \mathrm{~h}$ pulse at $5^{\circ} \mathrm{C}$ with $10^{-5} / 10^{-4} \mathrm{M}$ GA. After $16 \mathrm{~h}$ of ${ }^{14} \mathrm{C}_{-}-\mathrm{GA}_{3}$ uptake at $20^{\circ} \mathrm{C}$ relatively high levels of ${ }^{14} \mathrm{C}$ were found in leaves and low levels in stems and flowers. After this treatment about half of the ${ }^{14} \mathrm{C}-\mathrm{GA}_{3}$ in leaves was metabolized into unknown compounds.
\end{abstract}

\section{Introduction}

Detached leaves of many species show a rapid onset of yellowing, especially when held in the dark [15, 16]. In most plant species the net breakdown of chlorophyll in detached leaves is effectively delayed by natural cytokinins or compounds with cytokinin-activity [16]. In a number of species chlorophyll breakdown can be delayed by IAA [11, 15] or GA $[2,9,11]$.

Cut flowering branches of Alstroemeria pelegrina L., placed in water, show rapid leaf yellowing, even when held in the light. Preliminary experiments showed that in many cultivars visible yellowing started a few days after cutting and preceded the onset of petal wilting and abscission. Preliminary tests also showed that the inclusion of a mixture of IAA, GA and kinetin in the vase solution effectively delayed the onset of leaf yellowing in cut flowering branches of $A$. pelegrina [14].

The present investigation is a more detailed analysis of the effects of exogenous hormones on leaf yellowing in A. pelegrina, both in cut flowering

\footnotetext{
* Corrigendum. Owing to an error in the proofreading process, the article was published incorrectly. The article as it should have been published is presented here.
}

stems and in detached leaves. IAA, kinetin or GA were applied either as a $20 \mathrm{~h}$ pulse shortly after harvest, or as a continuous treatment in the solution. The distribution of GA in the cut flowering stem and the stability of GA in the tissue was also assessed, using ${ }^{14} \mathrm{C}-\mathrm{GA}_{3}$.

\section{Materials and methods}

\subsection{Plant material}

Cut flowering branches of Alstroemeria pelegrina $\mathrm{L}$. (cvs. Yellow King, Orchid, Flamingo, Marina, Carmen, Ontario) were obtained from commercial growers. Flowering stems with a stem length of about $45 \mathrm{~cm}$ were harvested at the commercial cutting stage and transported dry to the laboratory.

Five $\mathrm{cm}$ of the stems were cut in air and the leaves were stripped from the basal $10 \mathrm{~cm}$ of the stem. Stems were placed in pulse solutions containing appropriate hormone concentrations (at $5^{\circ} \mathrm{C}$ for 16 or $20 \mathrm{~h}$ in the dark). The stems were then placed in individual vases at $20^{\circ} \mathrm{C}, 60 \% \mathrm{RH}$ and a photosynthetically active quantum flux of $15 \mu \mathrm{mol} \mathrm{m}^{-2} \mathrm{~s}^{-1}$ (12h per day) from fluorescent tubes (Philips TLD $58 \mathrm{~W} / 84$ ). Alternatively, the 
vase solutions contained the same concentration of the hormones.

\subsection{Chemicals}

IAA was obtained from Merck, kinetin (furfurylaminopurine) from $\mathrm{BDH}$, commercial preparations containing a mixture of GAs from Serva and from Bendien (Naarden, The Netherlands), and $\mathrm{GA}_{3}$ from Sigma.

\subsection{Chlorophyll analysis}

The analysis of chlorophyll was according to Vernon [18], harvesting leaves only from the basal $25 \mathrm{~cm}$ of the stems.

\subsection{Distribution of ${ }^{14} \mathrm{C}-\mathrm{G} \mathrm{A}_{3}$}

Cut flowers were allowed to take up to $3.7 \times 10^{4} \mathrm{~Bq} \quad\left[1.7 .12 .18-{ }^{14} \mathrm{C}\right]-\mathrm{GA}_{3} \quad$ (Amersham, spec. act. $259 \mathrm{MBq} \mathrm{mmol}^{-1}$ ). In this experiment the isotope was mixed with SVB-1, a commercial preparation of GAs (Bendien, Naarden, The Netherlands). Total GA concentration in the solution was $20 \mathrm{mg} /$. Uptake for $16 \mathrm{~h}$ at $20^{\circ} \mathrm{C}$. Immediately after uptake at various levels of the stem 1 gram stem segments, single leaves and single flowers were cut, placed in polycarbonate cups and dried at $70^{\circ} \mathrm{C}$ for $24 \mathrm{~h}$. Dried samples were combusted in a L.S. Sample Oxidizer (IN 4101, Intertechnique). Radioactivity was dissolved in $10 \mathrm{ml}$ Carbomax (Lumac) and counted in a liquid scintillation spectrometer (Packard, A 300C).

\subsection{Stability of ${ }^{14} \mathrm{C}-\mathrm{GA}_{3}$ in the leaves}

Cut flowering branches were allowed to take up ${ }^{14} \mathrm{C}_{-}-\mathrm{GA}_{3}$ for $16 \mathrm{~h}$ as described above. Immediately after uptake about 1 gram of leaf mass was blended in $10 \mathrm{ml}$ cold methanol. This mixture was centrifuged at $5000 \mathrm{rpm}$ and supernatant evaporated under reduced pressure. The residue was loaded on a TLC plate [Silicagel F 254, Merck]. Chromatography was carried out with toluene/ butanol/acetic acid $(70 / 25 / 5 ; \mathrm{v} / \mathrm{v})$. Radioactivity on the plate was measured using a TLC scanner [Berthold, LB 2723].
Table 1. Effects of IAA, kinetin and $\mathrm{GA}_{3}$ on levels of chlorophyll $\mathbf{a}+\mathbf{b}$ in the basal leaves of cut flowering branches of Alstroemeria pelegrina L. (cv. Yellow King), 16 days after the onset of vase life. The initial concentration of chlorophyll $a+b$ was $17.4 \pm 1.5 \mathrm{~g}$ per $\mathrm{kg}$ fresh $\mathrm{wt}$. Analysis of variance and LSD test showed significant differences at $\mathrm{P}<5 \%\left(^{*}\right)$ or $\mathrm{P}<1 \%\left(^{* *}\right)$

\begin{tabular}{lccc}
\hline & & \multicolumn{2}{c}{ Chlorophyll $\mathrm{a}+\mathrm{b}(\mathrm{g}$ per kg fresh wt) } \\
\cline { 3 - 4 } & & $20 \mathrm{~h}$ pulse treatment & Continuous treatment \\
\hline IAA & $0 \mathrm{M}$ & $5.8 \pm 1.0$ & $5.8 \pm 1.0$ \\
& $10^{-7}$ & $6.4 \pm 1.2$ & $5.7 \pm 1.4$ \\
& $10^{-6}$ & $5.8 \pm 1.8$ & $3.9 \pm 1.4$ \\
& $10^{-5}$ & $6.1 \pm 2.1$ & $4.5 \pm 1.5$ \\
& $10^{-4}$ & $6.5 \pm 1.5$ & $3.8 \pm 1.3$ \\
Kinetin & 0 & $6.4 \pm 1.2$ & $6.4 \pm 1.2$ \\
& $10^{-7}$ & $6.0 \pm 1.8$ & $6.9 \pm 1.7$ \\
& $10^{-6}$ & $6.8 \pm 1.1$ & $6.1 \pm 1.4$ \\
& $10^{-5}$ & $6.5 \pm 1.1$ & $6.8 \pm 1.3$ \\
& $10^{-4}$ & $8.0 \pm 1.3$ & $10.2 \pm 1.8^{*}$ \\
$\mathrm{GA}_{3} \quad 0^{*}$ & $5.7 \pm 1.3$ & $5.7 \pm 1.3$ \\
& $10^{-7}$ & $5.4 \pm 1.8$ & $15.3 \pm 1.5^{* *}$ \\
& $10^{-6}$ & $9.8 \pm 1.4^{* *}$ & $15.9 \pm 1.0^{* *}$ \\
& $10^{-5}$ & $14.3 \pm 1.7^{* *}$ & $14.8 \pm 1.1^{* *}$ \\
& $10^{-4}$ & $15.5 \pm 1.9^{* *}$ & $15.6 \pm 1.4^{* *}$ \\
\hline
\end{tabular}

\section{Results}

\subsection{Effects of hormones}

When flowering stems of $A$. pepegrina (cv. Yellow King) were held in water at a photon flux density of $15 \mu \mathrm{mol} \mathrm{m}^{-2} \mathrm{sec}^{-1}$ (12 h per day) visible leaf yellowing occurred within 4-6 days after the onset of vase life. Leaf yellowing started in the basal leaves and was correlated with a decrease in chlorophyll levels. IAA had no positive effect at all tested concentrations, either in continuous treatment or after a $20 \mathrm{~h}$ pulse (Table 1). When given as a continuous treatment kinetin delayed chlorophyll breakdown at $10^{-4} \mathrm{M}$ (Table 1 ).

Including a commercial mixture of GAs or $\mathrm{GA}_{3}$ in the vase water was very effective in retaining chlorophyll. In $20 \mathrm{~h}$ pulse treatments the optimum concentration was $10^{-4} \mathrm{M}$, whereas in continuous treatment the same effect was found using a concentration of $10^{-7} \mathrm{M}$ (Table 1). The positive effect of GAs and $\mathrm{GA}_{3}$ was also observed in other tested cultivars (Orchid, Flamengo, Marina, Carmen, Ontario).

Chlorophyll breakdown in detached leaves from flowering $A$. pelegrina branches was not affected by IAA $\left(10^{-7}-10^{-4} \mathrm{M}\right)$, but was effectively delayed by 


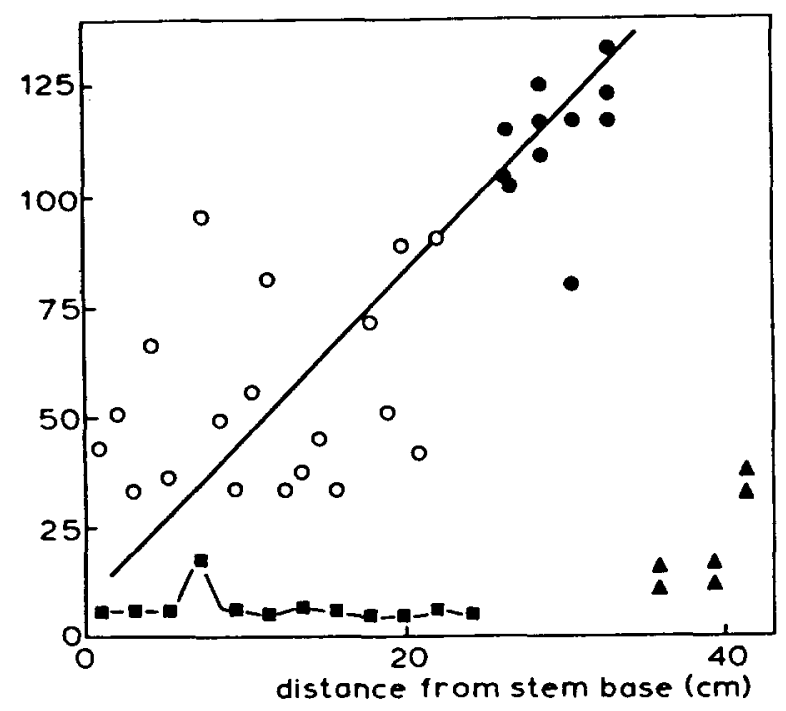

Fig. 1. Levels of radioactivity from ${ }^{14} \mathrm{C}-\mathrm{GA}_{3}$ in stems $(\boldsymbol{\square})$ ), basal leaves $(0)$, top leaves $(\bullet)$, and flowers $(\bullet)$, in cut flowering branches of Alstroemeria pelegrina L. (cv. Ontario) as dependent on the distance from the stem base. Treatment period was $16 \mathrm{~h}$.

a continuous treatment with $10^{-7} \mathrm{M}$ kinetin or $10^{-7} \mathrm{M} \mathrm{GA}_{3}$. The onset of yellowing in detached leaves occurred after the same period of time as in leaves attached to the cut flowering branches, and the rate of yellowing was similar in detached and attached leaves (results not shown).

\subsection{Distribution of ${ }^{14} \mathrm{C}-\mathrm{GA}$, after pretreatment}

After a $16 \mathrm{~h}$ pulse treatment of $A$. pelegrina cv. Ontario with ${ }^{14} \mathrm{C}_{-} \mathrm{GA}_{3}$ a relatively low level of radioactivity was found in stems and flowers, and a high level in leaves, especially those at the top of the flowering branch (Figure 1).

\subsection{Determination of reaction products from ${ }^{14} \mathrm{C}$ - $G A_{3}$}

After a $16 \mathrm{~h}$ pulse with ${ }^{14} \mathrm{C}-\mathrm{GA}_{3}$ about $50 \%$ of the label was found to cochromatograph with $\mathrm{GA}_{3}$ while about $50 \%$ was present in one (or more) unknown compound(s) (Figure 2).

\section{Discussion}

Of the investigated hormones, a low concentration

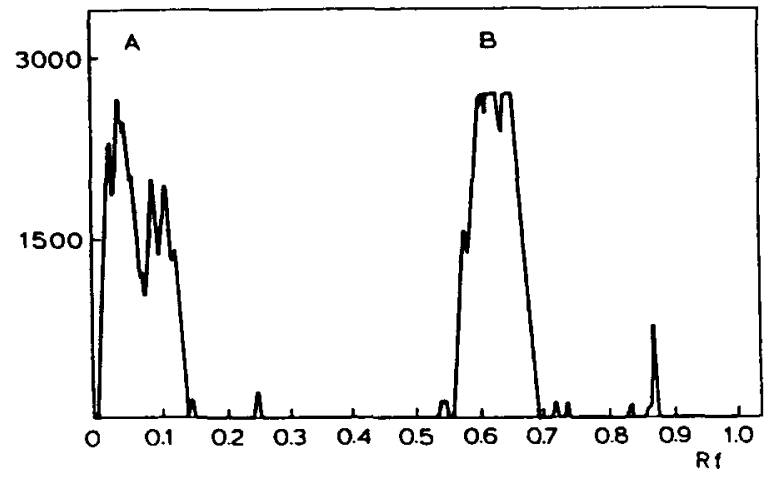

Fig. 2. Location of radioactivity in expressed sap from leaves of cut flowering branches of Alstroemeria pelegrina L. (cv. Ontario), after $16 \mathrm{~h}$ uptake of ${ }^{14} \mathrm{C}-\mathrm{GA}_{3}$. The extract was loaded on a TLC plate (solvent toluene/n-butano/acetic acid). The peak at B corresponds to $\mathrm{GA}_{3}$.

of mixed GAs or $\mathrm{GA}_{3}$ effectively delayed the onset of visible leaf yellowing and chlorophyll breakdown, both in cut leaves and in leaves attached to cut flowering stems of $A$. pelegrina. $\mathrm{GA}_{3}$ from Sigma may contain up to $10 \% \mathrm{GA}_{1}$ and $\mathrm{GA}_{1}$ may be the effective species in preparations of $\mathrm{GA}_{3}$ (Knegt, pers. comm.). Future research, therefore, has to establish which of the various GA molecules is actually causing the physiological response against leaf yellowing.

Effects of GA against leaf yellowing have been reported in detached leaves of a number of other species including Tropaeolum majus [2, 3, 4] Rumex obtusifolius, [7, 8] Pharbitis (=Ipomoea) nil, Hydrocotyle volgare, Triticum aestivum, Secale cereale, Avena sativa and Hordeum vulgare [9].

Yellowing in detached leaves in Tropaeolum majus [4] and Taraxacum officinale [8] was associated with a decrease in endogenous levels of GA. Yellowing of attached leaves in lettuce [1] and in cotyledons of intact cotton plants [5] was also associated with a marked decrease in free GA. These temporal correlations may suggest a role for endogenous GA in leaf yellowing.

We found that the onset of chlorophyll breakdown occurred after the same period in detached leaves and in leaves attached to the cut flowering stems, which may indicate that the signal(s) for the onset of senescence reside in the leaves.

In detached leaves of many plant species kinetin was also found to inhibit yellowing $[10,15]$. GA 
was as effective as kinetin in delaying leaf senescence in detached leaves of Taraxacum officinale [8], Rumex obtusifolius [7, 19] and in leaf discs of Tropaeolum majus [3]. In cut flowering branches of A. pelegrina we found only an effect of high concentrations of kinetin against leaf yellowing. Kinetin, however, delayed chlorophyll breakdown in detached leaves at relatively low concentrations.

A similar effect of kinetin was found with respect to the onset of the rise in ethylene production (and petal wilting) in cut carnation flowers. Kinetin was relatively ineffective in delaying petal wilting in flowers with a long stem, but effective in isolated petals or in flowers with a short stem $[6,12,17]$.

A pulse treatment with preparations containing GA has become mandatory for all flowering stems of $A$. pelegrina sold at the flower auctions in The Netherlands. The present paper confirms this practice and shows its importance for the cut flower trade.

\section{Acknowledgements}

We are grateful to G. van de Zandschulp and H.L. Honkoop for chlorophyll analysis, to C.R. Vonk and $H$. Dekhuyzen for critically reading the manuscript.

\section{References}

1 Aharoni N and Richmond AE (1978) Endogenous gibberellin and abscisic acid as related to senescence of detached lettuce leaves. Plant Physiol 62: 224-228

2 Beevers L (1968) Growth regulator control of senescence in leaf discs of nasturtium (Tropaeolum najus). In: F. Wightman, ed. Biochemistry and Physiology of Plant Growth Substances, 1417-1434. Ottawa: Runge

3 Beevers L and Guernsey FS (1976) Interaction of growth regulators in the senescence of nasturtium leaves during senescence. Nature 216:941-942
4 Chin $T$ and Beevers L (1970) Changes in endogenous growth regulators in nasturtium leaves during senescence. Planta 92: 178-188

5 Elkinawy M (1984) Hormonal change associated with leaf senescence in cotton (Gossypium barbadense). Physiol Plant 62: $593-598$

6 Eisinger W (1977) Role of cytokinins in carnation flower senescence. Plant Physiol 59: 707-709

7 Fletcher RA and Osborne DJ (1966) Gibberellin as a regulator of protein and ribonucleic acid synthesis during sensescence in leaf cells of Taraxacum officinale. Can. J. Bot. 44: 739-745

8 Fletcher RA, Oegema T and Horton RF (1969) Endogenous gibberellin levels and senescence in Taraxacum officinale. Planta 86: 98-102

9 Göring H (1987) Hormonal regulation of leaf growth and senescence in relation to stomatal movements. In: SS Purohit, ed. Hormonal Regulation of Plant Growth and Development, 201-219. Dordrecht: Martinus Nijhoff

10 Ilan I and Goren R (1979) Cytokinins and senescence in lemon leaves. Physiol Plant 45: 93-95.

11 Noodén LD (1988) Abscisic acid, auxin, and other regulation of senescence. in: LD Noodén and AC Leopold, eds. Senescence and Aging in Plants, 330-368. San Diego: Academic Press

12 Mor Y, Spiegelstein H and Halevy AH (1983) Inhibition of ethylene biosynthesis in carnation petals by cytokinin. Plant Physiol 71: 541-546

13 Osborne DJ (1962) Effects of kinetin on protein and nucleic acid metabolism of Xanthium leaves during senescence. Plant Physiol 18: 349-364

14 Staden OL (1973) Bestrijding van vroegtijdige bladvergeling bij alstroemeria op de vaas (Measures to counteract early leaf yellowing in alstroemeria flowers). In Dutch. Report no. 1956, Wageningen: Sprenger Institute

15 Thimann KV (1985) The interaction of hormonal and environmental factors in leaf senescence. Biol Plant 27: 93-91

16 Thomas $\mathrm{H}$ and Stoddart JL (1980) Leaf senescence. Ann Rev Plant Physiol 31; 83-111

17 Van Staden J (1989) Cytokinins and auxins in carnation senescence as related to chemical treatments. Acta Hortic 261: $69-80$

18 Vernon LP (1960) Spectrophotometric determination of chlorophyll and phaeophytin in plant extract. Anal Chem 32: 1144-1150

19 Whyte P and Luckwill LC (1966) Sensitive bioassays for gibberellins based upon retardation of leaf senescence in Rumex obtusifolius. Nature 210: 1360 